\title{
CÁLCULO EM MATEMÁTICA: UM ASSUNTO PARA O ENSINO EM GERAL OU ESPECÍFICO PARA O ENSINO TÉCNICO
}

DOI: http://dx.doi.org/10.1590/2236-3459/54093

\author{
Everaldo Paulo da Silva \\ Universidade Federal do Rio de Janeiro, Brasil. \\ Gert Schubring \\ Universidade Federal do Rio de Janeiro, Brasil.
}

$\cos 80$

\begin{abstract}
Resumo
No âmbito deste texto o nosso objetivo é seguir o caminho de Cálculo Diferencial e Integral na educação geral/ensino secundário e da educação profissional/ensino técnico no Brasil. Para realizar essa tarefa traçou-se um panorama histórico do século 20 , tendo como ponto de partida a Conferência Internacional sobre o Ensino de Matemática de Paris, em 1914, a legislação brasileira e os contextos políticos e econômicos que, por vezes, influenciaram a inclusão ou a extinção do Cálculo dos programas nacionais, e também acompanhar a trajetória do Cálculo na disciplina Matemática desde Escola Técnica Federal de São Paulo até sua transformação em Centro Federal de Educação Tecnológica, onde foi implantado, pela primeira vez, o ensino médio.

Palavras-chave: disciplina matemática, história do ensino de matemática, cálculo no ensino médio, história do cálculo.
\end{abstract}

\section{CALCULUS IN MATHEMATICS: A SUBJECT FOR TEACHING IN GENERAL OR SPECIFICALLY IN TECHNICAL EDUCATION}

\section{Abstract}

Our goal is to follow the path of Differential and Integral Calculus in General Education, secondary education, and Professional Education, technical education, in Brazil in a case study. To accomplish this task, we will make a historical overview of the twentieth century, taking as a starting point the International Conference on the Teaching of Mathematics in Paris in 1914, Brazilian legislation and the political and economic contexts that sometimes influenced either inclusion or exclusion of calculus of national programs, and also the Calculus trajectory in mathematics discipline of the Escola Técnica Federal de São Paulo until its transformation into the Centro Federal de Educação Tecnológica where the secondary education type became implemented for the first time.

Key-words: mathematics teaching, history of mathematics education, calculus in secondary school, history of calculus. 


\section{CÁLCULO EN LAS MATEMÁTICAS: ¿UN TEMA PARA LA ENSEÑANZA EN GENERAL O ESPECIFICO DE EDUCACIÓN TÉCNICA}

\section{Resumen}

Nuestro objetivo es analizar la trayectoria del Cálculo Diferencial e Integral en la Educación General, Educación Secundaria, y en la Educación Profesional, Educación Secundaria Modalidad Técnico Profesional, en Brasil en un estudio de caso. Para realizar esa tarea, desarrollaremos un panorama histórico del siglo 20, teniendo como punto de partida la Conferencia Internacional sobre la Enseñanza de Matemáticas en Paris, en 1914, la legislación brasileña y los contextos políticos y económicos que, en algún momento, influenciaron en la inclusión o la extinción del cálculo en los programas nacionales; y también la trayectoria del cálculo en la disciplina de matemáticas de la Escuela Técnica Federal de São Paulo hasta su transformación para el Centro Federal de Educación Tecnológica, donde fue implantado la educación secundaria.

Palabras-clave: enseñanza de las matemáticas; historia de la educación matemática; cálculo en la escuela secundaria; historia de cálculo.

\section{CALCUL EN MATHÉMATIQUES: UN SUJET DE L'ENSEIGNEMENT EN GÉNÉRAL OU SPÉCIFIQUE A L'ÉDUCATION TECHNIQUE}

\section{Résumé}

Notre objectif est de suivre la trajectoire du Calcul Différentiel et Intégral dans l'Enseignement General, enseignement secondaire. et l'Enseignement Professional, enseignement technique, au Brésil dans une étude de cas. Pour accomplir ce tâche, nous ferons un survol historique du 20ème siècle, qui aura comme point de départ la Conférence Internationale sur l'Enseignement des Mathématique à Paris en 1914, les lois brésiliennes et les contextes politiques et économiques qui ont parfois influencé l'inclusion, ou l'exclusion du calcul infinitésimal des programmes nationaux, et aussi la trajectoire de ce Calcul dans l'enseignement des mathématiques dans la Escola Técnica Federal de São Paulo jusqu'à sa transformation en le Centro Federal de Educação Tecnológica où l'enseignement secondaire a été mis en œuvre pour la première fois.

Mots-clé: l'enseignement des mathématiques, histoire de l'enseignement des mathématiques, calcul infinitésimal à l'école secondaire, l'histoire de calcul infinitésimal. 


\section{Introdução}

S escolas técnicas federais, originárias das escolas de aprendizes artífices,
tornaram-se autônomas antes da LDB de 1961 e seus programas eram
definidos pela comissão de professores de cada instituição. No caso da Escola Técnica Federal de São Paulo, o Cálculo esteve presente nos programas desde antes de 1970 e foi elemento central na disciplina durante os últimos trinta anos de existência da escola.

No projeto de ensino médio do Centro Federal de Educação Tecnológica de São Paulo - Cefet/SP -, o Cálculo deixou de fazer parte da disciplina Matemática. Note-se que o Cálculo é central para o pensamento funcional, pois além de propiciar subsídios para o debate sobre continuidade, de interesse acadêmico, tem ampla aceitação nas atividades complexas da vida moderna e contemporânea, de interesse aplicado e quando o Cefet/SP excluiu o Cálculo dos programas da disciplina Matemática no ensino médio adotou tendência de uma matemática que não tem por finalidade o Cálculo como a coroação do desenvolvimento curricular, assim como pensado por Félix Klein (1849-1925).

Nosso objetivo é acompanhar a trajetória do Cálculo Diferencial e Integral na educação geral, ensino secundário, e na educação profissional, ensino técnico, no Brasil. Para realizar esta tarefa partiremos a Conferência Internacional do Ensino de Matemática, ocorrida em 1914 em Paris, as legislações brasileiras e contextos políticos e econômicos que influenciaram, ora a permanência, ora a extinção do Cálculo nos programas nacionais e a trajetória do Cálculo na disciplina Matemática da Escola Técnica Federal de São Paulo até sua transformação em Centro Federal de Educação Tecnológica.

Entendemos que a análise única e exclusiva das determinações legais não é suficiente para esclarecer a dinâmica que envolve um conteúdo programático ou um currículo escolar. Viñao (2008) e Schubring (2005) defendem uma abordagem que também ultrapasse as análises isoladas de um currículo e suas determinações ou prescrições legais. É preciso olhar para os livros-texto, para a prática dos professores e para a constituição destes enquanto categoria profissional, além de sua prática em sala de aula.

Entender o sistema de educação brasileiro também se fez necessário para compreendermos a dinâmica em que a escola se encontra. Assim, estudar os programas explícitos é essencial para vermos como este processo se desenrola. Além disso, ainda de acordo com Schubring,

como os programas representam intenções - da parte de certos grupos dominantes da comunidade educativa respectiva e, por outro lado, da política do ministério, uma agência centralizada, agindo alegadamente de uma maneira benevolente - as realizações no ensino podem ser bastante diferentes e, assim, os programas significam somente um fator de importância. (2005, p. 6)

Para melhor compreendermos as transformações ocorridas ao longo deste século fixaremos nosso olhar sobre o ensino de Cálculo Diferencial e Integral da seguinte forma: o movimento internacional de reforma, educação geral/ensino secundário, educação profissional/ensino técnico, currículo da Escola Técnica Federal de São Paulo. 


\section{O movimento internacional de reforma}

Em 1914 aconteceu em Paris a Conferência Internacional do Ensino de Matemática. Um dos resultados foi um extenso relatório do movimento de reforma internacional no ensino de Matemática. Este movimento de reforma surgiu a partir da criação da Internationalen Mathematischen Unterrichtskommission - Imuk atual ICMI - International Commission on Mathematics Instruction, idealizada por seu presidente, Félix Klein, em 1908 (Gispert; Schubring, 2011).

O movimento, inspirado nas ideias do professor Félix Klein foi ousado ao propor uma reforma de tamanha proporção. Para Klein a disciplina Matemática deveria propiciar aos alunos de nível intermediário elementos que pudessem remontar o estudo da Matemática enquanto área de conhecimento. Klein percebera problemas entre a Matemática estudada e praticada na escola e aquela estudada e praticada no ensino superior. Alguns destes problemas eram o distanciamento entre os conteúdos estudados em ambas as modalidades, secundário e superior, além de um atraso entre estes conteúdos. Esta disciplina escolar fora dividida em grupos de subdisciplinas que se relacionavam pouco ou quase nada com as ensinadas nas universidades. Tal distanciamento fazia com que aquele que desejasse tornar-se professor desta disciplina tivesse que esquecer a Matemática da escola enquanto estivesse na universidade para, em seguida, esquecer a Matemática acadêmica quando retornasse às salas de aula na escola (Schubring, 2014a). Este fenômeno também é conhecido como duplo rompimento (Kilpatrick, 2008). É neste contexto que a proposta de uma reforma que incluísse a ensinar os elementos do Cálculo foi elaborada e difundida.

O relatório da Conferência Internacional do Ensino de Matemática de 1914 apresenta detalhes sobre esta iniciativa de reformas nos seguintes países: Alemanha, Austrália, Áustria, Bélgica, Brasil, Dinamarca, Estados Unidos, França, Holanda, Hungria, Ilhas Britânicas, Itália, Noruega, Romênia, Rússia, Sérvia, Suécia e Suíça ${ }^{1}$. A reforma pretendia alcançar a todas as instituições de ensino secundário, principalmente aquelas que antecediam imediatamente o ensino superior.

O relatório do delegado brasileiro sobre a conferência (Beke, 1914) indica que o Cálculo Diferencial e Integral era ministrado junto com a Geometria Analítica e que este conteúdo vigorou no Brasil de 1891 até 1901, de modo a ser suprimido e não mais constar dos programas do secundário até a data do referido congresso. Um relatório mais detalhado seria produzido pelo professor Eugênio de Barros Raja Gabaglia, representante brasileiro na conferência, o que não aconteceu.

No Brasil foi publicado o decreto n. 891 , de 8 de novembro de 1890 , conhecido como reforma Benjamin Constant, que, a princípio, não refletiu explicitamente, mas antecipou alguns elementos do movimento de reforma proposto pela Imuk iniciado em 1908. No artigo 30 o decreto determinava, para a primeira cadeira do terceiro ano, o conteúdo "Geometria geral e o seu complemento algébrico. Cálculo diferencial e integral, limitado ao conhecimento das teorias rigorosamente indispensáveis ao estudo da mecânica geral propriamente dita" (art. 30, terceiro ano, $1^{\text {a }}$ cadeira, decreto número 981 de 8 de novembro de 1890).

\footnotetext{
${ }^{1}$ Relatório na íntegra, em inglês, ver Schubring (2014b). \begin{tabular}{l|l|l} 
Hist. Educ. (Online) & Porto Alegre & v. 20
\end{tabular}
} ก. 49 Maio/ago., 2016 p. $65-80$ 
Durante os poucos anos em que vigorou, a reforma Benjamin Constant não representou grande mudança no ensino de Matemática no país, pois os estabelecimentos de ensino secundário eram em número reduzido no território brasileiro. No Colégio Pedro II, por exemplo, os conteúdos do Cálculo permaneceram no currículo de 1889 a 1899 , extintos a partir de 1900 e retomados em 1929 (Carvalho, 1996).

O Brasil da Primeira República ainda era um país de economia predominantemente baseada na agricultura, com reduzidos polos industriais que não iam além da produção manufaturada de insumos agrícolas. É importante observar que entre final do século 19 e o começo do século 20 a Europa já vivia um crescimento industrial acelerado e que os setores econômicos pressionavam as demandas de adequação à modernização, inclusive na educação. O primeiro movimento de reforma internacional respondeu a estes processos de modernização da sociedade. Já no Brasil o processo de industrialização só iria acontecer com força a partir da década de 1930, quase 15 anos após a referida conferência.

Os esforços de uma reforma internacional foram interrompidos pelas sucessivas guerras e as atividades do ICMI seriam retomadas apenas em 1952. O Brasil acolheu influências deste movimento internacional de reforma, principalmente a partir do trabalho do professor Euclides Roxo.

\section{Educação geral: ensino secundário}

A ideia de ensino secundário no Brasil é muito difusa, pois os critérios de classificação deste nível de ensino alteraram-se em diversos momentos no decorrer do século 20 , com os diferentes decretos e leis publicados.

Atualmente o termo ensino médio é aquele que melhor representa este nível de ensino. As finalidades deste nível também variaram ao longo do século. Contudo, podemse apontar duas características invariantes para este nível de ensino: foi oferecido àqueles que cursaram uma etapa inicial denominada ensino primário ou primeiras letras, atual ensino fundamental, e se constitui numa etapa necessária para acessar ao ensino superior.

$\mathrm{Na}$ criação das escolas profissionais e das escolas normais não houve a preocupação de continuidade de estudos no ensino superior. As escolas profissionais e escolas normais tinham uma finalidade diferente do secundário, que preparava para o ensino superior, até a Lei de Diretrizes e Bases da Educação de 1961. Com a promulgação da LDB estas modalidades de ensino passaram a integrar, tanto a mesma base do ensino de grau médio, quanto sua outra finalidade específica. Excetuam-se aqui os colégios militares, que respondem a uma legislação própria.

Para que possamos melhor compreender os caminhos do programa de Matemática no secundário, tomaremos como ponto de partida o Colégio Pedro II. A escolha deste colégio deve-se por ele ter permanecido até o ano de 1961 como referência legal para o ensino secundário no Brasil e, principalmente, por ser a partir dele que encontramos dois personagens relevantes na constituição da disciplina Matemática no Brasil: o professor Eugênio de Barros Raja Gabaglia e o professor Euclides de Medeiros Guimarães Roxo. 
Eugênio de Barros Raja Gabaglia foi professor e diretor do Colégio Pedro II. O relatório da Conferência Internacional do Ensino de Matemática de 1914 (Beke, 1914) aponta o professor Raja Gabaglia como o representante brasileiro, mas não fica clara a participação do brasileiro no evento.

O professor Euclides Roxo ocupou a cadeira do professor Raja Gabaglia no Colégio Pedro II e foi responsável por diversas mudanças dentro desta instituição. Entre elas pode-se citar a unificação de um conjunto de matérias sob a denominação única de Matemática. Roxo foi entusiasta das propostas de reforma apresentadas pelo ICMI e das ideias do professor Félix Klein. Segundo Dassie e Rocha (2003), pode-se dizer que

\begin{abstract}
Euclides Roxo [...] era um seguidor de Félix Klein, quanto à maneira de entender $\mathrm{o}$ ensino da matemática. Em todos os seus trabalhos, especialmente em seus artigos, mostrava-se basicamente um defensor do pensamento do matemático alemão. Todos os vários autores que cita, bem como os pareceres de associações que utilizava em suas manifestações, têm sempre o objetivo de respaldar as ideias divulgadas por esse grande professor de Göttingen. (p. 67)
\end{abstract}

Roxo teve, ainda, um papel fundamental na elaboração dos programas da reforma Francisco Campos. Os programas de Matemática contemplavam amplamente a introdução ao Cálculo com características semelhantes a do movimento internacional de reforma. Dassie e Rocha (2003) apresentam as evidências da função de Roxo:

Euclides Roxo ocupou posição central na elaboração dos novos programas de matemática estabelecidos com a Reforma Francisco Campos para o Curso Fundamental. Várias evidências apontam no sentido de que, basicamente, foi ele quem os organizou e redigiu, bem como as instruções para sua aplicação. Tal constatação baseia-se em uma sequência de fatos, quais sejam: a posição que ele ocupava de Diretor do Internato do Colégio Pedro II (ocupou tal cargo de 1930 a 1935), o que lhe permitiu acesso ao Ministro da Educação e Saúde; os seus próprios depoimentos; o testemunho do Padre Arlindo Vieira, reitor do Colégio Santo Inácio, um dos maiores críticos às mudanças implementadas; as palavras do professor das Escolas Técnicas Secundárias, Paulo F. R. Mendes Vianna; e, ainda, o conteúdo desses programas, bem como as ideias que emanavam de suas instruções pedagógicas. (p. 68)

\title{
Reforma Francisco Campos
}

A reforma Francisco Campos foi um conjunto de decretos implantados pelo governo Vargas e visou à organizar os ensinos secundário e superior no Brasil ${ }^{2}$.

No âmbito do secundário houve uma mudança substancial em relação ao determinado anteriormente na reforma Benjamin Constant. Destacamos aqui algumas destas mudanças:

${ }^{2}$ Decreto n. 19.850, de 11 de abril de 1931, que criou o Conselho Nacional; decreto n. 19.851, da mesma data, que dispôs sobre a organização do ensino superior no Brasil e adotou o regime universitário; decreto n. 19.852, também da mesma data, que dispôs sobre a organização da Universidade do Rio de Janeiro; decreto n. 19.890, de 18 de abril de 1931, que dispôs sobre a organização do ensino secundário; decreto n. 19.941, de 30 de abril de 1931, que instituiu o ensino religioso como matéria facultativa nas escolas públicas do País; decreto n. 20.158, de 30 de junho de 1931, que organizou o ensino comercial e regulamentou a profissão de contador; decreto n. 21.241, de 14 de abril de 1932, que consolidou as disposições sobre a organização do ensino secundário. 
a) extinção dos exames parcelados: com a reforma Benjamin Constant os alunos poderiam se apresentar para as provas finais ou de madureza realizando uma única avaliação por disciplina sem, necessariamente, frequentarem as aulas. Após a reforma Francisco Campos os alunos eram obrigados a frequentar as aulas regularmente. Pelo art. 33 do decreto 19.890, de 18 de abril de 1931, impõe-se o mínimo de 75\% de presença e a realização de exames periódicos de avaliação para trocarem de série (Carvalho; Dassie, 2012);

b) mudança do secundário de cinco para sete anos divididos em dois ciclos: um fundamental de cinco anos e outro complementar de dois anos. O ciclo complementar, preparatório para as universidades, era dividido em três modalidades, cada qual visando a uma área distinta que abrangia os cursos superiores existentes: estudos jurídicos, medicina, farmácia e odontologia e engenharia e arquitetura;

c) implantação do serviço de inspeção que atribuía a um inspetor a emissão mensal de relatório dirigido ao Departamento Nacional de Ensino sobre a fiscalização dos estabelecimentos de ensino.

Os programas para o ciclo curso complementar do secundário foram publicados somente no ano de 1936, pela portaria ministerial s/n de 17 de março, já na administração do ministro Capanema. Nestes programas o conteúdo do Cálculo tinha enfoque em aplicações geométricas e cinemáticas. O conceito de derivadas devia ser apresentado como taxa de variação e como velocidade instantânea e os conceitos de integrais associados ao cálculo de áreas e volumes.

\section{Reforma Capanema}

Entre 1935 e 1945 o Ministério da Educação e Saúde foi administrado por Gustavo Capanema. Nesta administração criou-se o Serviço Nacional de Aprendizagem Industrial Senai - e organizou-se os ensinos industrial, secundário e comercial ${ }^{3}$. O ensino agrícola teve sua organização publicada somente em 1946, sob a administração do ministro Netto Campelo Júnior e do presidente Eurico Gaspar Dutra.

Nesta época o secundário continuava dividido em duas partes denominadas ginasial, com duração de cinco anos, e colegial, com duração de três anos. Este ainda foi subdividido em duas modalidades, o científico e o clássico, substituindo as três modalidades do anterior curso complementar.

Dassie (2001) aponta a participação de Roxo na estruturação do ensino secundário e na elaboração dos programas específicos de Matemática, tanto na reforma Francisco Campos, quanto na reforma Capanema, e notamos que apesar da disciplina Matemática ser tratada como um conteúdo único, nos programas ela ainda aparece subdividida em Aritmética, Álgebra, Geometria e Trigonometria.

$\mathrm{Na}$ portaria ministerial n. 177, de 16 de março de 1943, são apresentados os programas para os cursos Clássicos e Científicos da Reforma Capanema. Analisando o texto publicado notamos que na parte de Álgebra, onde comumente ficavam organizados os conteúdos do Cálculo, não aparece nenhuma referência ao conteúdo do Cálculo

3 Decreto-lei n. 4.048, de 22 de janeiro de 1942, cria o Serviço Nacional de Aprendizagem dos Industriários; decreto-lei n. 4.073, de 30 de janeiro de 1942, Lei orgânica do ensino industrial; decreto-lei n. 4.244, de 9 de abril de 1942, Lei Orgânica do Ensino Secundário; decreto-lei 6.141, de 28 de dezembro de 1943, Lei Orgânica do Ensino Comercial; decreto-lei n. 9.613, de 20 de agosto de 1946, Lei Orgânica do Ensino Agrícola. 
Integral, nem mesmo para o curso científico, que possui um grupo maior de assuntos em Matemática em relação ao curso Clássico. Há apenas a referência de dois assuntos que aparecem desvinculados da Álgebra que são os estudos de variações e das derivadas, porém, não há indicações de abordagens geométricas ou cinemáticas, como já constou em legislações anteriores.

O conteúdo que trata das integrais, das primitivas e das abordagens geométricas e cinemáticas só retornaram oficialmente aos programas na portaria ministerial n. 1.045 , de 14 de dezembro de 1951, que trata sobre os planos do desenvolvimento dos programas mínimos de ensino secundário e instruções metodológicas. Estes programas permaneceram inalterados até a promulgação da Lei de Diretrizes e Bases da Educação em 1961.

\section{Educação profissional: ensino técnico}

Em 1909, o então presidente da República Nilo Peçanha criou, pelo decreto n. 7.566, de 23 de setembro, as Escolas de Aprendizes Artífices. Estas escolas são a primeira manifestação de uma rede de ensino profissional nacional. No entanto, este tipo de escola estava longe de atender às demandas profissionais daquele começo de século. A ideia da criação dessa escola consta no próprio texto do decreto, o qual considera que

o augmento constante da população das cidades exige que se facilite às classes proletárias os meios de vencer as dificuldades sempre crescentes da luta pela existência: que para isso se torna necessário, não só habilitar os filhos dos desfavorecidos da fortuna com o indispensável preparo técnico e intelectual, como fazê-los adquirir hábitos de trabalho profícuo, que os afastara da ociosidade ignorante, escola do vicio e do crime; que é um dos primeiros deveres do Governo da República formar cidadões úteis à Nação.

Decreta:

Art. $1^{\circ}$. Em cada uma das capitais dos Estados da República o Governo Federal manterá, por intermédio do Ministério da Agricultura, Indústria e Comércio, uma Escola de Aprendizes Artífices, destinada ao ensino profissional primário gratuito.

Paragrapho único. Estas escolas serão instaladas em edifícios pertencentes à União, existentes e disponíveis nos Estados, ou em outros que pelos governos locais forem cedidos permanentemente para o mesmo fim. (Decreto 7.566 de 23 de abril de 1909)

O ensino profissional, criado naquele momento, não tinha a finalidade de atender às demandas da classe industrial, comercial ou agrícola, mas a uma modalidade de assistência aos desafortunados e adolescentes em condições de abandono.

Nestas instituições eram oferecidos o ensino primário e um curso de Desenho. Entretanto, o conteúdo dos cursos deveriam ser determinados pelo diretor da escola, conforme $\mathrm{o}$ artigo $9^{\circ}$ deste mesmo decreto.

Estas escolas eram vinculadas ao Ministério de Agricultura, Indústria e Comércio, situação que permaneceu até a lei n. 378, de 13 de janeiro de 1937, quando a Escola de Aprendizes Artífices passou a denominar-se Liceu Industrial e foi integrada ao Ministério de Educação e Saúde. 
Em torno do ensino profissional uma discussão foi travada durante a Era Vargas: a quem interessava um ensino profissional? Neste cenário, atendendo à demanda do setor industrial, é criado o Serviço Nacional de Aprendizagem Industrial - Senai.

O Senai foi criado pelo decreto-lei n. 4.048, de 22 de Janeiro de 1942, a primeira lei da reforma Capanema, e dava à Confederação Nacional da Indústria - CNI - plenos poderes para a organização do ensino profissional, especificamente o ensino industrial. Deste modo tivemos dois sistemas de ensino profissional: o do governo, organizado pelo Ministério da Educação e Saúde que administrava as escolas técnicas, e o do setor privado, representado pelo CNI que administrava o Senai (Carvalho, 2011).

No mesmo mês de criação do Senai o governo Vargas publicou o decreto-lei $n$. 4.073, de 30 de janeiro de 1942, a terceira lei da reforma Capanema, organizando o ensino industrial. Já existiam alguns poucos centros que ofereciam cursos técnicos, mas é a partir desta legislação que o ensino industrial passou a expedir certificados oficiais:

A lei n. 3.991, de 5 de janeiro de 1920, autorizava o Ministério da Agricultura, Indústria e Comércio (não havia ainda Ministério da Educação) a estabelecer convênios com estabelecimentos para o funcionamento do curso de química industrial com a duração de três anos. Posteriormente, foram instalados cursos de eletrotécnica no Instituto Eletrotécnico de Itajubá (MG), assim como na Escola de Engenharia Mackenzie (SP), local onde também funcionava um curso de química industrial. No entanto, esses cursos não podiam expedir certificados oficiais porque eram "livres", assim como os cursos de química industrial, citados primeiramente. (D'Ângelo, 2007, p. 93)

A Reforma Capanema inaugurou o ensino técnico como parte do ensino industrial, composto de três modalidades: o curso de formação profissional, articulado com o ensino primário; o curso técnico, articulado com o primeiro ciclo do secundário; e o curso pedagógico, oferecido para os que quisessem integrar o quadro administrativo ou docente no curso técnico. Aqueles que fossem concluintes do ensino técnico só poderiam matricular-se em cursos superiores que fossem diretamente ligados ao curso técnico concluído.

Mesmo com esta característica fica evidente que o ensino técnico não é equivalente ao ensino secundário, uma vez que os oriundos deste poderiam se matricular em qualquer curso superior. Os primeiros sinais da equiparação entre estas duas modalidades de ensino aparecem em duas legislações antes da unificação em 1961: a lei n. 1.076, de 31 de março de 1950, estabeleceu que os concluintes dos cursos normal e técnico - industrial, comercial ou agrícola - poderiam se matricular no clássico ou no científico, modalidades do secundário, e a lei n. 1.821, de 12 de março de 1953, que facultava aos egressos dos cursos técnicos e normal matricular-se em quaisquer cursos superiores. A aprovação dos egressos em processo vestibular era necessário para o acesso ao ensino superior em ambas legislações.

As escolas de ensino industrial federais tiveram autonomia didática, administrativa, técnica e financeira a partir da lei n. 3.552 de 16 de fevereiro de 1959. Isto fez com que as escolas não tivessem que manter uma estrutura única e favorecia as características regionais de cada escola. Neste sentido, vemos a Escola Técnica Federal de São Paulo como uma experiência peculiar de uma rede de ensino técnico nacional. 
Diferente do ocorrido nos países europeus, a industrialização no Brasil teve seu auge um pouco mais tarde, especificamente a partir do governo Getúlio Vargas (19301945).

No começo do século 20, à exceção do que ocorreu no resto do país, a cidade de São Paulo começou a se transformar em centro financeiro nacional onde os produtores de café do interior paulista se aglomeravam para negociar seus produtos. A economia paulista, fortemente baseada na produção e exportação de café, principalmente pelas vantagens encontradas pelo grão na terra roxa do interior paulista, trouxe um grande contingente de trabalhadores oriundos de outros países que vinham trabalhar na produção. Escravos libertos e imigrantes formaram as primeiras populações de trabalhadores da metrópole. Este grande contingente que começou a se aglomerar na cidade fez com que a economia local ficasse mais independente. Algumas indústrias começaram a prosperar à medida que supriam as demandas locais de tecidos, telhas, ferramentas, tijolos.

Estas indústrias se fortaleceram e alteraram o cenário econômico da região, de modo que os industriais tiveram um acúmulo considerável de capital tornando-os mais independentes em relação às políticas de exportação adotadas pelo governo federal na década de 1930. Neste contexto, o ensino técnico no Estado de São Paulo cresceu de modo acelerado e já em 1969 possuía uma rede estadual composta por seis escolas. Ainda de acordo com D'Ângelo (2007),

o Senai possuía em São Paulo duas escolas, uma na Guanabara e outra escola no Rio Grande do Sul. As escolas isoladas, aquelas que tinham administração autônoma e não formavam redes eram as mais numerosas. Em 1969 existiam em todo país 68 escolas isoladas e 113 escolas técnicas sendo que 34 delas se situavam no Estado de São Paulo. Essas escolas isoladas eram formadas por empresas industriais, que instalavam escolas técnicas para preparar seus trabalhadores para seu quadro de funcionários, como a Fundição Tupy, a Companhia Siderúrgica Nacional, a Companhia de Aços Especiais Itabira e a Companhia Ferro Brasileiro. Também formavam escolas isoladas, entidades governamentais como as universidades federais e a Marinha de Guerra, mantendo escolas ou cursos técnicos. (D'Ângelo, 2007, p. 100)

Os currículos das escolas técnicas eram divididos em dois ou mais grupos de disciplinas: as disciplinas de cultura geral e disciplinas técnicas. Analisando o quadro de disciplinas e carga horária da ETFSP do ano de 1970 foi possível observar três grupos de disciplinas denominadas disciplinas de cultura geral, disciplinas de cultura técnica específica e práticas educativas.

As disciplinas de cultura geral compreendiam Português, Matemática, Química, Física, Biologia, História $\mathrm{E}$ Línguas. Este núcleo de disciplinas equivalia à, aproximadamente, $30 \%$ do curso técnico. A disciplina Matemática ocupava a maior parte destas disciplinas ocupando também $29 \%$ da cultura geral.

As disciplinas de cultura técnica específica eram compostas das disciplinas técnicas. No caso do curso de Mecânica, um dos mais antigos da escola as disciplinas no ano de 1970 eram: Desenho, Eletrotécnica, Prática Profissional, Resistência dos Materiais e Ensaios Tecnológicos, Tecnologia dos materiais, Ferramentas e das Máquinas Operatrizes, Organização e Métodos. 
As disciplinas técnicas teóricas - Eletrotécnica, Resistência dos Materiais e Ensaios Tecnológicos, Tecnologia dos materiais, Ferramentas e das Máquinas Operatrizes Organização e Métodos - ocupavam 24,5\% das disciplinas de cultura geral técnica, Desenho ocupava 19,7\% e Prática Profissional 36\% destas disciplinas.

As disciplinas que compunham as práticas educativas eram Educação Moral e cívica, Educação Física e Organização Social e Política Brasileira.

Matemática tem uma participação muito grande nas disciplinas de cultura geral no currículo desta instituição. Este grande espaço ocupado teve características muito mais específicas que geral, como veremos mais adiante. Porém, as determinações legais não garantiram a permanência dos conteúdos definidos até a legislação de 1961 para o secundário, de modo que as escolas técnicas reorganizaram suas disciplinas, inclusive a Matemática.

\section{Currículo da Escola Técnica Federal de São Paulo}

Ao analisar os programas oficias da Escola técnica Federal de São Paulo observamos algumas alterações explícitas que o programa da Disciplina Matemática sofreu.

Do material disponível escolhemos analisar os programas com intervalos de aproximadamente dez anos, uma vez que as alterações anuais eram pouco significativas. Outros dois problemas encontrados em nossa pesquisa foi a dificuldade em acessar ao arquivo permanente e a escassez de documentos anteriores a década de 1970. O Instituto Federal de São Paulo, até o presente momento, não possui um trabalho de organização sistematizada de seu arquivo, o que nos custou demasiado tempo para conseguirmos autorização de acesso ao acervo e organizar as informações que encontramos.

A organização do currículo de Matemática na escola é unificado, salvo o caso do curso Técnico em Edificações, que faz uma inversão na ordem dos conteúdos, apresentando os elementos de Geometria Métrica já no primeiro ano do curso.

Convém informar que os grupos de disciplinas denominadas Disciplinas Técnicas ainda complementavam diversos assuntos em Matemática e Física, como é o caso das disciplinas Desenho Técnico e Resistência dos Materiais, que não foram incluídas nestes estudos por não serem base comum do ensino secundário e por terem seus conteúdos adequados a cada curso oferecido pela escola.

Foram analisados os programas da disciplina Matemática dos cursos de Mecânica, Eletrotécnica, Processamento de Dados, Telecomunicações e Eletrônica.

Para melhor percebemos o que acontece com o conteúdo de cálculo, fizemos duas separações sobre o mesmo conteúdo. Em geral entendemos que o Cálculo é indissociável do conteúdo de Funções, uma vez que este é ponto central dos estudo das variações de funções. Porém, o modo como a organização dos programas foi elaborado nos fez optar por uma separação destes assuntos de modo a explicitar a mudança que percebemos. Assim, dividimos o conteúdo do estudo das Funções e do Cálculo em duas partes: Pré-Cálculo e Cálculo. 
Com o nome Pré-Cálculo entendemos todo o conteúdo explicito nos programas que discute teoria dos conjuntos e funções. Neste tópico destacamos em especial as funções polinomiais, logarítmicas, exponenciais e circulares. Com o nome Cálculo entendemos os conteúdos que contém única e exclusivamente os estudos de limites, derivadas e integral.

Mais uma vez ressaltamos que esta separação só faz sentido para analisar estes dados em específico e que em nada condiz com a forma com que estes conhecimentos foram desenvolvidos, pois, historicamente, não existiu tal linearidade na evolução destes conceitos.

No gráfico a seguir percebemos que no ano de 1974 o Pré-Cálculo e o Cálculo eram apresentados durante quase todo o segundo ano. Em 1983 e 1999 o Pré-Cálculo já acontece em quase todo o primeiro ano e é retomado como uma espécie de revisão curta antes do Cálculo, que será ministrado no segundo ano. Em 2005 o conteúdo de Cálculo deixa de fazer parte do currículo, restando apenas o conteúdo de Pré-Cálculo.

Notamos, ainda, que o número de aulas de Cálculo não sofreu significativas mudanças durante os anos 1974, 1983 e 1994, variando de 45 e 46 aulas. Já a quantidade de aulas de Pré-Cálculo sofreu uma grande variação em relação ao total verificado entre 1974 e 1983, passando de 25 aulas para 97 aulas. Até o ano de 1994 o total de aulas atingiu 98 e em 2005 ficou reduzido para 88 aulas.

Observar as variações do total de aulas não nos põe, obrigatoriamente, frente a uma situação precisa, pois os tempos de cada aula possivelmente variaram ao longo destes trinta anos analisados. Não tivemos acesso, porém, a dados mais específicos destas variações. No entanto, foi-nos possível apresentar a proporção das aulas de Cálculo e Pré-Cálculo em relação ao número total de aulas da Disciplina Matemática nos três anos dos curso técnico e médio.

Gráfico 1 -

Distribuição das disciplinas relativas ao curso técnico e ensino médio.

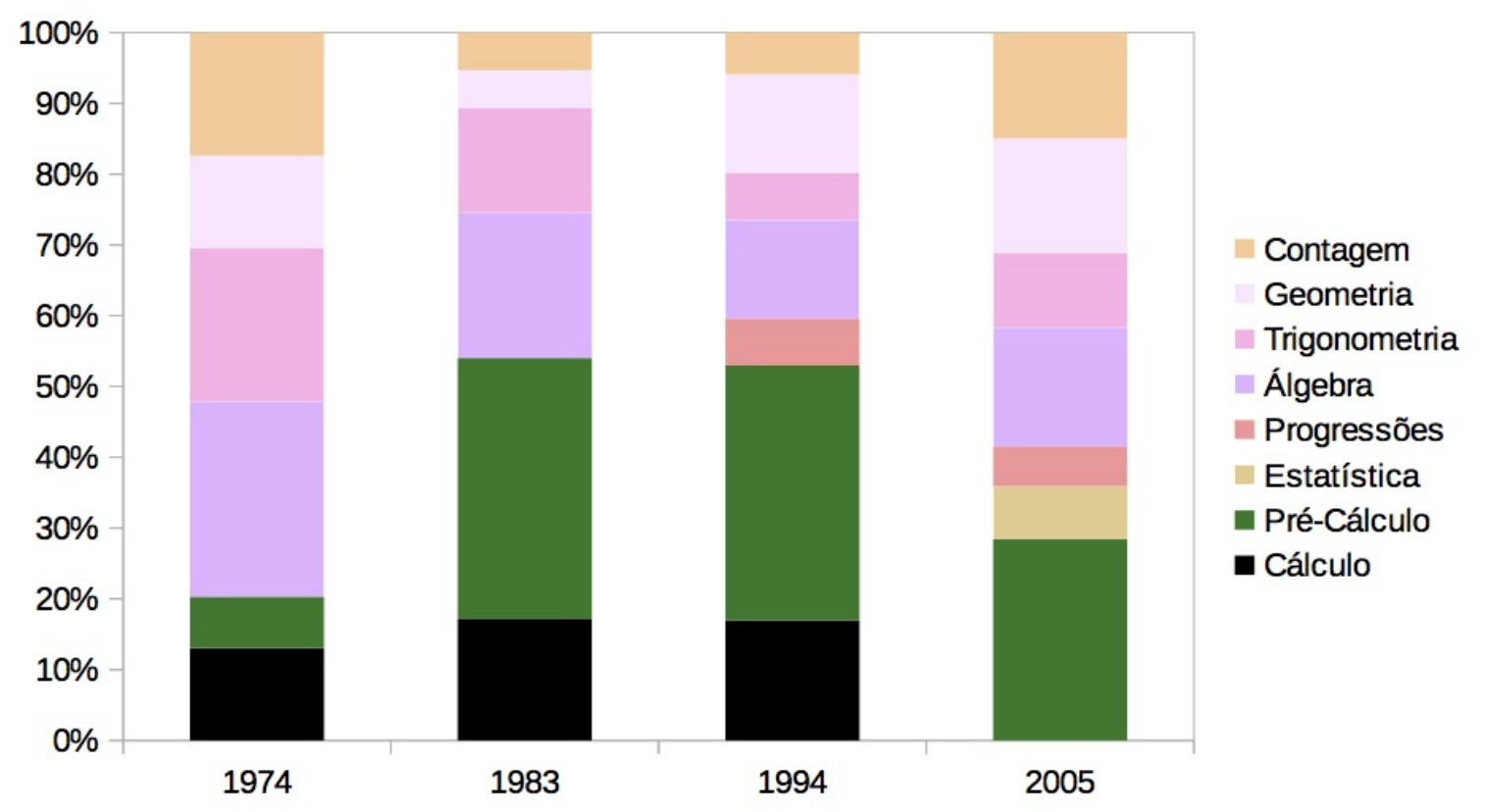


Podemos acompanhar as variações que os conteúdos da disciplina sofreram nestes, aproximadamente, trinta anos. No currículo de 1994 aparece um conteúdo novo, as Progressões Aritmética e Geométrica. No currículo de 2005 outro assunto é englobado pela disciplina, a Estatística. Salvo estas novas entradas e a saída do Cálculo em 2005 a estrutura da disciplina se manteve, porém, a diferença consistia nos espaços que elas ocupavam dentro da disciplina Matemática.

Aqui podemos notar a importância que o Pré-Cálculo foi adquirindo ao longo dos anos em relação ao total de aulas do curso na disciplina Matemática e, ainda, o quanto no sentido contrário o Cálculo deixa de ser central na mesma disciplina para ensino médio. Se, em 1974, a disciplina Matemática era classificada como disciplina de cultura geral, contendo a Introdução ao Cálculo, em 2005, com a saída do Cálculo da disciplina Matemática, fica evidente a estreita relação que o conteúdo tinha com as matérias técnicas.

\section{Considerações finais}

Euclides Roxo, quando elaborou os programas do ensino secundário, tanto no colégio Pedro II, quanto nas reformas Campos e Capanema, manteve o Cálculo como elemento central de um pensamento funcional nos moldes do movimento de reforma. As poucas mudanças no conteúdo da disciplina Matemática levaram o Cálculo até a Lei de Diretrizes e Bases de 1961, que incumbiu a tarefa de elaboração de novos programas para o CFE. O Conselho Federal de Educação, por sua vez, não elaborou os programas para o currículo da disciplina Matemática em detrimento de outras demandas principalmente relacionadas a criação de entidades privadas de ensino.

Na década de 1960 os grupos de estudos de educação matemática de São Paulo influenciavam diversos grupos de estudos pelo país difundindo um novo modo de se ensinar matemática. Neste sentido, o Movimento de Matemática Moderna conseguiu bastante visibilidade e preencheu a lacuna deixada pelo governo quanto ao conteúdo para a disciplina Matemática, publicando livros e oferecendo cursos para professores, se ocupando em difundir a concepção estruturalista fundada nas relações e conjuntos, bastante reproduzida nos livros-textos e processos vestibulares.

Se o pensamento em Klein era o raciocínio funcional para a preparação ao Cálculo como elemento central das distâncias entre o secundário e o superior, independente do modelo de escola secundária, na ETFSP o Cálculo se manteve como elemento central da disciplina apenas sob a ótica de complementar a formação técnica, apesar de a disciplina Matemática fazer parte do grupo de disciplinas de cultura geral. Deste modo, a persistência do Cálculo divergia da concepção de Klein para este conteúdo. A supressão do conteúdo no ensino médio do Cefet/SP guarda apenas uma parte do movimento de reforma baseado no pensamento funcional, que no desenrolar das décadas de 1960 a 1990 converteram características mais próximas da Matemática Moderna.

Sob a ótica do movimento internacional de reforma promovido por Klein a partir de 1908, o que ocorreu no Brasil teve características distintas daquelas pensada pelo professor alemão e percebidas em outros países. O Cálculo, na ETFSP, foi a ligação entre o saber do ensino secundário e o saber do ensino superior. O Cálculo, como conteúdo de cultura geral e elemento de ligação entre a matemática do cotidiano e a matemática do ensino superior, não aconteceu no ensino médio desta instituição, ou seja, 
não se incorporou aos conteúdos de cultura geral para o ensino médio. Os programas deixam de preparar para o Cálculo e para continuidade dos estudos, para exclusivamente preocupar-se com o cotidiano e com as aplicações práticas para o ensino médio.

\section{Referências}

BEKE, Emanuel. Les résultats obtenus dans l'introduction du calcul différentiel et intégral dans les classes supérieures des établissements secondaires: rapport général l'enseignement mathématique. v. 16. Paris, 1914, p. 245-284.

BRASIL. Decreto n. 2.208 de 17 de abril de 1997. Regulamenta o $\S 2{ }^{\circ}$ do art. 36 e os arts. 39 a 42 da lei n. 9.394, de 20 de dezembro de 1996, que estabelece as diretrizes e bases da educação nacional. Brasília, 1997.

BRASIL. Decreto n. 5.154 de 23 de julho de 2004. Regulamenta o $\S 2^{\circ}$ do art. 36 e os arts. 39 a 41 da lei n. 9.394, de 20 de dezembro de 1996, que estabelece as diretrizes e bases da educação nacional, e dá outras providências. Brasília, 2004.

BRASIL. Decreto n. 7.566, de 23 de setembro de 1909. Cria nas capitais dos estados as escolas de aprendizes artífices, para o ensino profissional primário e gratuito. Rio de Janeiro, 1909.

BRASIL. Decreto n. 981, de 8 de Novembro de 1890. Aprova o regulamento da instrução primária e secundária do Districto Federal. 1890.

BRASIL. Decreto-lei n. 4.127, de 25 de fevereiro de 1942. Estabelece as bases de organização da rede federal de estabelecimentos de ensino industrial. Rio de Janeiro, 1942.

BRASIL. Lei n. 3.552. de 16 de fevereiro de 1959. Dispõe sobre nova organização escolar e administrativa dos estabelecimentos de ensino industrial do Ministério da Educação e Cultura e dá outras providências. Rio de Janeiro, 1959.

BRASIL. Lei n. 1.076, de 31 de março de 1950. Assegura aos estudantes que concluírem curso de primeiro ciclo do ensino comercial, industrial ou agrícola, o direito à matrícula nos cursos clássico e científico e dá outras providências. Rio de Janeiro, 1950.

BRASIL. Lei n. 1.821, de 12 de Março de 1953. Dispõe sobre o regime de equivalência entre diversos cursos de grau médio para efeito de matrícula no ciclo colegial e nos cursos superiores. Rio de Janeiro, 1953.

BRASIL. Lei n. 378, de 13 de janeiro de 1937. Dá nova organização ao Ministério da Educação e Saúde Pública. Rio de Janeiro, 1937.

BRASIL. Lei n. 4.024, de 20 de dezembro de 1961. Lei de diretrizes e bases da educação nacional: fixa as diretrizes e bases da educação nacional. Brasília: MEC, 1961.

BRASIL. Lei n. 5.692, de 11 de agosto de 1971. Fixa diretrizes e bases para o ensino de $1^{\circ}$ e $2^{\circ}$ graus, e dá outras providências. Brasília: MEC, 1971.

BRASIL. Lei n. 9.394, de 20 de dezembro de 1996. Estabelece as diretrizes e bases da educação nacional. Brasília, 1996.

BRASIL. Lei n. 3.991, de 5 de janeiro de 1920. Fixa a despesa geral da República dos Estados Unidos do Brasil para o exercício de 1920. Rio de Janeiro, 1920.

BRASIL. Lei n. 8.948 de 8 de dezembro de 1994. Dispõe sobre a instituição do sistema nacional de educação tecnológica e dá outras providências. Brasília, 1994. 
BRASIL. Portaria ministerial n. 177, de 16 de março de 1943. Expede os programas de matemática dos cursos clássico e científico do ensino secundário. Diário Oficial da União. Rio de Janeiro, 1943, p. 3930-3931. Disponível em <http://www.jusbrasil.com.br/ diarios/2211641/pg-18-secao-1-diario-oficial-da-uniao-dou-de-18-03-1943/pdfView>.

Acesso em 20 fev. 2015.

BRASIL. Portaria ministerial n. de 1045 de 14 de dezembro de 1951. Expede os planos do ecodesenvolvimento dos programas mínimos de ensino secundário e respectivas instruções metodológicas. Diário Oficial da União. Rio de Janeiro, n. 45, 22 fev. 1952, p. 7-9. Disponível em <http://www.jusbrasil.com.br/diarios/2375341/pg-73-secao-1-diariooficial-da-uniao-dou-de-22-02-1952/pdfView>. Acesso em 20 fev. 2015.

BRASIL. Portaria ministerial s/n de 17 de março de 1936. Dispõe sobre os programas do curso complementar - Matemática. Diário Oficial da União. Rio de Janeiro, ano L20V, n. 66, 19 mar. 1936, p. 5791-5825. <Disponível em:https://repositorio.ufsc.br/bitstream/ handle/123456789/104320/1936\%20-\%20Portaria\%20Ministerial\%20-\%20DOU\%2019-

03-1936\%20-\%20Programas \%20do\%20curso\%20complementar.pdf?sequence=1>.

Acesso em 20 fev. 2015.

CARVALHO, Joao Bosco Pitombeira F. Algumas considerações históricas sobre o ensino de cálculo na escola secundária. Cadernos Cedes, Campinas, v. 40, 1996, p. 62-81.

CARVALHO, Joao Bosco Pitombeira F; DASSIE, Bruno Alves. The history of mathematics education in Brazil. ZDM - The International Journal on Mathematics Education. Karlsruhe, v. 44 , n. 4,2012 , p. $499-511$.

CARVAlHO, Marcelo Augusto Monteiro de. A criação do Senai no contexto da Era Vargas. São Paulo: USP, 2011. 192f. Dissertação (mestrado em História Econômica). Universidade de São Paulo.

CENTRO FEDERAL DE EDUCAÇÃO TECNOLÓGICA DE SÃO PAULO. Plano de curso (ensino médio). São Paulo, 2005.

D’ANGELO, Márcia. Escola técnica federal de São Paulo: a integração do saber e do fazer na formação do técnico de nível médio (1985-1986). São Paulo: USP, 2007. 353f. Tese (doutorado em História). Faculdade de Filosofia, Letras e Ciências Humanas, Universidade de São Paulo.

DA SILVA, Everaldo Paulo. A matemática no Conselho Federal de Educação: resgate de uma trajetória e as concepções sobre uma disciplina. ENCONTRO BRASILEIRO DE PESQUISA EM ENSINO DE MATEMÁTICA, 17, 2013. Anais ... Vitória: Ebrapem, 2013. <Disponível em ftp://ftp.ifes.edu.br/cursos/Matematica/EBRAPEM/GDs/GD05/Sessao2/ Sala_B1/920-1762-1-PB.pdf>. Acesso em 20 fev. 2015.

DASSIE, Bruno Alves; ROCHA, José Lourenço da. O ensino de matemática no Brasil nas primeiras décadas do século 20. Caderno Dá-Licença, n. 4, ano 5, 2003, p. 65-73.

DASSIE, Bruno. Alves. A matemática do curso secundário na reforma Gustavo Capanema. Rio de Janeiro: PUCRJ, 2001. 170f. Dissertação (mestrado em Matemática). Departamento de Matemática. Pontifícia Universidade Católica do Rio de Janeiro.

ESCOLA TÉCNICA FEDERAL DE SÃO PAULO. Livro de planejamento educacional. São Paulo, 1974.

ESCOLA TÉCNICA FEDERAL DE SÃo PAULO. Plano de ensino. São Paulo, 1983. ESCOLA TÉCNICA FEDERAL DE SÃO PAULO. Plano de ensino. São Paulo, 1995. 
GISPERT, Hélène; SCHUBRING, Gert. Societal, structural, and conceptual cahnges in mathematics teaching: reform and processes in france and germany over the twentieth century and the international dinamics. Science in context. New York, v. 24, n. 1, 2011, p. 73-106.

KILPATRICK, Jeremy. The development of mathematics education as an academic field. In: FURINGHETTI, Fúlvia, MENGHINI, Marta. GIACARDI, Lívia; ARZARELLO, Ferdinando. The first century of International Commission on Mathematical Instruction (1908-2008): reflecting and shaping the world of mathematics education. Roma: Istituto della Encyclopedia Italiana, 2008, p. 25-39.

NUNES, Edson de Oliveira; BARROSO, Helena Maria; FERNANDES, Ivanildo Ramos. Do CNE ao CNE: 80 anos de política regulatória. FÓRUM SOBRE OS 15 ANOS DO CNE E 100 ANOS DOS CONSELHOS DE EDUCAÇÃO DO BRASIL. Brasília: CNE, 2011.

SARAIVA, Suzana Barros Corrêa. Conselho Federal de Educação (1961-1994): uma trajetória ideológica. Rio de Janeiro: UFRJ, 1999. 221f. Tese (doutorado em Educação). Universidade Federal do Rio de Janeiro.

SCHUBRING, Gert. Pesquisar sobre a história do ensino de matemática: metodologia, abordagens e perspectivas. In: MOREIRA, Darlinda; MATOS, José Manuel. História do ensino da matemática em Portugal. Lisboa: SPCE, 2005, p. 5-20.

SCHUBRING, Gert. A matemática elementar de um ponto de vista superior: Félix Klein e a sua atualidade. GIRALDO, Victor Augusto; ROQUE, Tatiana Marins. O saber do professor de matemática: ultra-passando a dicotomia entre didática e conteúdo. São: Moderna, 2014a, p. 39-56.

SCHUBRING, Gert. Classical papers in mathematics education: results obtained in the introduction of differential and integral calculus in upper grades of secondary institutions Emanuel Beke with introduction by Gert Schubring. The international Journal for the history of mathematics Education, v. 9, n. 1, New York, 2014b, p. 33-70.

VIÑAO FRAGO, Antonio. A história das disciplinas escolares. Revista Brasileira de História da Educação, Curitiba, n. 18, 2008, p. 173-215.

EVERALDO PAULO DA SILVA é licenciado em Matemática pelo Instituto de Matemática e Estatística da Universidade de São Paulo, mestre em Ensino de Matemática pela Universidade Federal do Rio de Janeiro.

Endereço: Avenida Brigadeiro Trompowski s/n - 21941-972 - Ilha do Fundão - Rio de Janeiro - RJ - Brasil.

E-mail: everaldops@gmail.com.

GERT SCHUBRING é pesquisador aposentado pela Faculdade de Matemática da Universidade de Bielefeld e professor visitante no Instituto de Matemática da Universidade Federal do Rio de Janeiro.

Endereço: Avenida Brigadeiro Trompowski s/n - 21941-972 - Ilha do Fundão - Rio de Janeiro - RJ - Brasil.

E-mail: gert.schubring@uni-bielefeld.de.

Recebido em 10 de março de 2015.

Aceito em 19 de outubro de 2015. 